\title{
Algunas propuestas para promover/destrabar inversiones (en serio) - El caso del sector regulatorio sanitario
}

\begin{abstract}
En el presente artículo, el Profesor Gutiérrez Bendezú propone alternativas innovadoras respecto a los bienes y servicios relacionados al sector de sanidad. Asimismo, evalúa cuales son las problemáticas actuales impuestas por nuestro ordenamiento y sugiere como solucionarlas para fomentar las inversiones.
\end{abstract}

Alvaro Gutiérrez Bendezú 


\section{Algunas propuestas para promover/destrabar inversiones (en serio) - El caso del sector regulatorio sanitario}

Cada vez que escuchamos a los políticos o empresarios decir que la clave para superar los problemas económicos del país pasa por fomentar las inversiones, por destrabar los proyectos de inversión o por darle seguridad jurídica a los inversionistas, se nos viene a la mente las imágenes de aquellas películas épicas griegas donde el "héroe" (el Ministro o el proyecto minero de turno), pelea contra el "monstruo" (el organismo de la administración pública o el grupo social que "no cree en la inversión"), donde el "bien" y el "mal" se enfrentan y uno de los dos termina muerto o al borde de la muerte.

Ciertamente la vida real es un poco más compleja que la ficción, con el agravante que en las últimas peleas épicas que hemos visto en el Perú casi siempre el "héroe" termina aniquilado.

Sin embargo, pasada la tormenta (y hasta que una nueva crisis asome), los problemas se mantienen, con lo cual siguen siendo válidos estos cuestionamientos: ¿Cómo se destraba realmente las inversiones? ¿Se necesita un escenario a largo plazo con reformas institucionales complejas? ¿Es un problema de "buenos" y "malos"?

Durante el tiempo que me tomó escribir este artículo, (i) un nuevo proyecto minero de importancia para el Perú fue enviado a la congeladora, principalmente por la falta de voluntad de las partes para cumplir y hacer cumplir la Ley; (ii) el dólar alcanzó un valor máximo de S/3.30; (iii) la Bolsa de Valores china tuvo una caída de $8.5 \%$; y (iv) los escándalos políticos escalan a pesar que no se ha iniciado aún la campaña presidencial para el 2016.

Como no es la primera vez que estos hechos ocurren en el país afectando las inversiones llamémoslas "macro", es necesario enfocarnos en el sector "micro" para explorar algunos sectores que sólo requieren que la Ley se cumpla (sin "mesas de negociación", protestas callejeras, toma de carreteras u otros mecanismos extra legales), o que en todo caso se realicen modificaciones normativas que permitan generar un flujo de inversiones que por acumulación sectorial puedan representar un interesante porcentaje del PBI del Perú.

Basados en la experiencia previa, alcanzamos algunos ejemplos en el ámbito de la regulación sanitaria que podrían servir para orientar las acciones del Estado y del sector privado para que -ordenadamente-, puedan alcanzar los objetivos que realmente importan (que el Perú deje de ser un país subdesarrollado), a través de la promoción y facilitación de inversiones "micro".

En efecto, el sector de la regulación sanitaria requiere un especial análisis pues a diferencia de otros ámbitos empresariales, los productos sometidos a esos controles sólo pueden comercializarse si es que antes han obtenido un permiso del Estado (léase, un registro sanitario o una notificación sanitaria obligatoria); es decir, para vender un 
producto regulado (sea un farmacéutico, un alimento o bebida industrializada, o un plaguicida químico de uso agrícola), necesito que el Estado me autorice su comercialización de manera previa y expresa.

La Dirección General de Medicamentos, Insumos y Drogas (DIGEMID), la Dirección General de Salud Ambiental (DIGESA) y el Servicio Nacional de Sanidad Agraria (SENASA) son las tres entidades estatales responsables de expedir los registros sanitarios para la importación y comercialización de los productos regulados que se encuentran bajo su competencia.

DIGEMID tiene a su cargo la regulación de los productos farmacéuticos (p.e. un antibiótico), dispositivos médicos (p.e. un implante dental) y productos sanitarios (p.e. un shampoo). Asimismo, tiene competencias para la regulación de los establecimientos que se dedican a la comercialización de estos productos (establecimientos farmacéuticos y no farmacéuticos).

Así, de acuerdo a nuestro marco legal, solo aquellos establecimientos constituidos societariamente en el Perú y autorizados previamente por DIGEMID tienen la facultad de fabricar, importar, almacenar y en general comercializar productos farmacéuticos, dispositivos médicos y productos sanitarios.

Por su parte DIGESA -entre otras facultades-, se encarga principalmente de la regulación de los alimentos y bebidas industrializados, es decir, de aquellos productos finales destinados al consumo humano, obtenidos por "transformación física, química o biológica de insumos de origen vegetal, animal o mineral y que contiene aditivos alimentarios"1.

Ambas entidades (DIGEMID y DIGESA) son órganos de línea que pertenecen al Ministerio de Salud.

Finalmente, SENASA es un organismo público adscrito al Ministerio de Agricultura, y es la entidad competente -entre otras funciones-, de la regulación de los plaguicidas químicos y biológicos de uso agrícola (principalmente).

De esta manera, a través del registro sanitario el Estado tiene la potestad de controlar el comercio de determinados productos en función al riesgo sanitario que éstos conllevan. En la medida que el riesgo sea más alto (p.e. un plaguicida químico), los requisitos regulatorios serán más estrictos, por lo cual el Estado puede reservarse el derecho de autorizar o no la comercialización de determinado producto basado en la posible afectación a la salud de las personas.

Sin perjuicio de ello, a partir de este punto podemos alcanzar algunas propuestas en el sector regulatorio sanitario para facilitar el comercio de estos productos.

1 Artículo 102 del Reglamento sobre Vigilancia y Control Sanitario de Alimentos y Bebidas (aprobado mediante Decreto Supremo 007-98-SA). 


\section{I. ¿"Registro sanitario" y "Notificación sanitaria obligatoria" son lo mismo?}

Es necesario mencionar una diferencia que atañe a un grupo de productos bajo regulación de DIGEMID, que son los productos cosméticos (incluidos en la categoría de "productos sanitarios"). En efecto, mientras que para la comercialización de productos farmacéuticos es necesario obtener previamente un registro sanitario, en el caso de los cosméticos el requisito de Ley es cumplir con una Notificación Sanitaria Obligatoria. Ahora bien, ¿es esta una diferencia meramente formal? No lo es. Por el contrario, es una diferencia sustancial que pasamos a explicar.

La razón por la cual algunos productos requieren obtener previamente a su comercialización un registro sanitario (RS), es debido al riesgo para la salud que conllevan estos productos. Así, en la medida que el riesgo del producto sea mayor (p.e., un plaguicida químico), los requisitos serán más estrictos. Por el contrario, un producto que no conlleve asociado un riesgo importante para la salud (p.e. un jabón), no requerirá de mayores controles por parte del Estado.

En consecuencia, para aquellos productos de riesgo importante para la salud (p.e. farmacéuticos o plaguicidas), el Estado se reserva el derecho de evaluarlos previamente y -luego de un análisis exhaustivo- podrá conceder autorización para su comercialización en el territorio peruano. Esta autorización se traduce en la concesión por parte de la autoridad competente de un "registro sanitario", lo que implica necesariamente la admisión, evaluación y pronunciamiento de la solicitud de registro dentro de un plazo determinado y posteriormente autorizar o no la comercialización de dichos productos.

Sin embargo, a diferencia de lo que sucede con el registro sanitario, la "Notificación Sanitaria Obligatoria" no requiere ninguna evaluación o aprobación previa por parte del Estado en el sentido de descartar algún riesgo para la salud por el uso de los productos, sino la simple verificación documental de los requisitos exigidos por Ley, luego de lo cual se debería permitir de manera automática la comercialización del producto en territorio peruano.

Es necesario destacar que la regulación de los productos cosméticos se rige por normas de la Comunidad Andina y -supletoriamente-, por las disposiciones legales internas peruanas. Ello es así desde que en el año 2002 la Comisión de la Comunidad Andina, en su calidad de órgano comunitario encargado de emitir normas legales supranacionales de aplicación directa en Bolivia, Colombia, Ecuador y Perú, emitió la Decisión 516 (titulada "Armonización de Legislaciones en Materia de Productos Cosméticos"). 
Al respecto, el Artículo 6 de la Decisión $516^{2}$ es claro al indicar que, "se entiende por Notificación Sanitaria Obligatoria la comunicación en la cual se informa a las Autoridades Nacionales Competentes, bajo declaración jurada, que un producto cosmético será comercializado a partir de la fecha determinada por el interesado".

En la parte considerativa de esta norma andina se menciona además lo siguiente:

"el desarrollo experimentado por los Países Miembros ha servido para constatar que el control en el mercado es un elemento de mayor eficiencia en la supervisión y garantía de la calidad de los productos, lo cual permite sustituir la solicitud del registro sanitario, como mecanismo de acceso al mercado de los cosméticos, por el mecanismo más ágil y sencillo de la Notificación Sanitaria Obligatoria".

Nótese que es la propia normativa andina la que establece los alcances del registro sanitario para diferenciarlo de la notificación sanitaria obligatoria, por lo cual debe quedar claro que para el comercio de estos productos se elimina cualquier intervención previa del Estado para la concesión del permiso para la comercialización de productos cosméticos, con lo cual los productores o importadores sólo deberán presentar los documentos que estén expresamente señalados en las normas andinas y la autoridad inmediatamente deberá permitir su comercialización.

En efecto, el Artículo 8 de la Decisión 516 señala lo siguiente:

"La Autoridad Nacional Competente, al recibir la Notificación Sanitaria Obligatoria correspondiente, revisará que esté acompañada de los requisitos exigidos, caso en el cual, sin mayor trámite, le asignará un código de identificación para efectos del etiquetado y de la vigilancia y control sanitario en el mercado. Los demás Países Miembros reconocerán el código asignado".

Queda claro entonces que el cambio de "Registro Sanitario" a "Notificación Sanitaria Obligatoria" no fue un asunto meramente "cosmético" sino responde a una necesidad producto de la evolución del mercado en el sentido de permitir a productos de bajo riesgo sanitario (cosméticos) que puedan ser comercializados sin mayores restricciones, sin perjuicio de las acciones posteriores de vigilancia y control que tienen las autoridades competentes.

2 La anterior norma comunitaria andina sobre comercialización de cosméticos (Decisión 412), establecía en su Artículo 13 que el registro sanitario se emitía dentro de los veinte días hábiles siguientes a la presentación de la solicitud. Sin embargo, la Decisión 412 disponía que si vencía ese plazo sin que se haya denegado el registro, éste se consideraba aprobado (es decir, se aplicaba el silencio administrativo positivo). 
Sin perjuicio de lo expuesto, obtener un código de identificación de Notificación Sanitaria Obligatoria puede tomar entre 3 a 4 semanas en el Perú (a pesar que la norma indica que este código debe asignarse "sin mayor trámite"), por lo cual un primer paso para agilizar las inversiones en este sector debe pasar necesariamente por cumplir la normativa andina y asignar estos códigos de NSO con la celeridad exigida por Ley.

\section{II. ¿Por qué no se cumplen los plazos para otorgar el registro sanitario de productos farmacéuticos?}

El antiguo Reglamento de Productos Farmacéuticos y Afines (aprobado mediante Decreto Supremo 010-97-SA), establecía que el registro sanitario de productos farmacéuticos se concedía en siete días hábiles y presentando un mínimo de documentación técnica.

Con la entrada en vigencia de la Ley 29459 ("Ley de los productos farmacéuticos, dispositivos médicos y productos sanitarios") y sus Reglamentos ${ }^{3}$, los plazos para la concesión del registro de estos productos varían entre 45 días a 12 meses, y se requiere la presentación de mayor sustentación técnica. Sin embargo, en algunos casos la obtención del registro sanitario de estos productos puede tardar algunos años.

Conforme hemos explicado anteriormente, los productos sometidos a la regulación sanitaria necesitan contar con un registro sanitario para su comercialización, por lo cual aquellas empresas que desean incursionar en el mercado peruano por primera vez. se ven con la sorpresa que sus productos no pueden ser comercializados precisamente por la demora en la obtención de los registros sanitarios.

¿Por qué se ha llegado a esta situación? En mi opinión, la respuesta para precisamente por la aprobación de la Ley 29459, norma que de manera ambiciosa pretendió elevar los estándares regulatorios sanitarios sin tener en cuenta que para lograr dicha mejora es necesario contar al mismo tiempo con los recursos humanos y técnicos adecuados. Es decir, se requería de una capacitación técnica al personal y dotar de una mejor infraestructura a la autoridad regulatoria.

Sin embargo, habiendo transcurrido más de cuatro años de la entrada en vigencia de la Ley, creemos que la autoridad regulatoria ya ha desarrollado las fortalezas necesarias para cumplir con los plazos para la concesión de los registros sanitarios, lo cual ciertamente es una primera señal para facilitar la llegada de nuevos productos farmacéuticos, dispositivos médicos y productos sanitarios al Perú.

Reglamento de Establecimientos Farmacéuticos, aprobado mediante Decreto Supremo 014-2011-SA, y Reglamento para el Registro, Control y Vigilancia Sanitaria de Productos Farmacéuticos, Dispositivos Médicos y Productos Sanitarios, aprobado mediante Decreto Supremo 016-2011-SA, en adelante, el "Reglamento de Productos Farmacéuticos". 


\section{III. ¿Por qué una empresa no domiciliada en el Perú no puede ser titular de registros sanitarios en nuestro país?}

El Reglamento de Productos Farmacéuticos dispone en su Artículo 8 que "pueden solicitar registro sanitario quienes cuenten con la autorización sanitaria como laboratorio de productos farmacéuticos, dispositivos médicos o productos sanitarios o como droguerías". Es decir, sólo aquellos establecimientos constituidos societariamente en el Perú y que además cuenten con la autorización de DIGEMID para funcionar como laboratorio o droguería será capaz de solicitar y obtener un registro sanitario. Con ello, las empresas farmacéuticas (e inclusive las empresas de alimentos industrializados) no domiciliadas en el Perú, no pueden ser titulares de estos registros y deben hacerlo a través de sus distribuidores peruanos, lo cual en la práctica genera una serie de problemas que detallamos a continuación.

El principal problema es que para la autoridad regulatoria, como el titular "legal" del registro es el distribuidor peruano, no le reconoce ningún derecho al titular "real" de dicho registro, a pesar que es el propio fabricante del producto farmacéutico. Así, se da la situación extrema que, debido a desavenencias comerciales entre la empresa farmacéutica y el distribuidor, el titular "legal" (el distribuidor) puede incluso cancelar un registro sanitario sin que el titular "real" pueda hacer algo para impedir dicha cancelación. Tengamos presente que la cancelación de un registro sanitario implica que automáticamente no podrá comercializarse el producto autorizado bajo ese registro.

De otro lado, el titular "real" tampoco puede obtener un nuevo registro sanitario mientras que el titular "legal" siga siendo el propietario del registro inicial.

Y muchas veces el titular "legal" le exige pagos exorbitantes al titular "real" para transferirle los registros sanitarios.

¿No sería más práctico (como sucede en otros países), que las empresas extranjeras puedan ser también titulares de registros sanitarios sin necesidad de estar constituidas como laboratorios o droguerías en el Perú?

Ciertamente deberá asegurarse los mecanismos para que estas empresas asuman la responsabilidad sobre los productos registrados, pero el hecho que las mismas no tengan un domicilio en el Perú no debe ser el motivo para no pensar en una alternativa eficiente para favorecer el ingreso de nuevos productos.

\section{IV. ¿Puedo vender "marcianos" en las bodegas sin correr el riesgo de ser denunciado por DIGESA?}

Hace algunos meses Franco Giuffra publicó en un diario local un artículo que no por ser, digamos, curioso, no deja de ser cierto. ¿Qué sucedería si en el verano usted quisiera 
vender "marcianos" (helados de fruta) en las bodegas? Pues tendría que obtener previamente un registro sanitario ante DIGESA, y para ello, dice Giuffra lo siguiente:

"Para venderlos en las bodegas, sin embargo, necesitará obtener un registro sanitario. Difícil, porque usted tiene planeado elaborarlos con agua de acequia y usando frutas podridas que recogerá en el mercado de su barrio. Para que salgan baratitos, seguramente.

Difícil, pero no imposible. Para tramitar el registro, compre un helado de cualquier marca reputada y lávese bien las manos. Diluya el helado y métalo ahora en su bolsita de marciano y listo. Ya tiene el producto con la garantía de que no está contaminado. Llévelo a analizar a cualquier laboratorio acreditado, complete unos formularios y la Dirección General de Salud Ambiental (Digesa) le entregará su registro sanitario válido por cinco años, previo pago de 380 soles. Ya puede volver a casa a producir sus marcianos como le dé la gana, incluso con la pila de su perro"4.

¿Es esto cierto? Lamentablemente sí. El registro sanitario de alimentos y bebidas industrializados se concede sobre la base de una declaración jurada que presenta el solicitante, en la cual tiene que informar cuáles son los ingredientes del producto (incluyendo aditivos), presentar los análisis físico-químico y microbiológicos del producto, las etiquetas, y una serie de requisitos adicionales; por ejemplo, si se trata de un producto elaborado en el extranjero, debe presentarse un documento que acredite que ese producto se vende libremente en ese país (este es el denominado Certificado de Libre Venta o CLV). La autoridad revisa el cumplimiento de estos requisitos y -en un plazo legal de siete días hábiles-, concede el respectivo registro sanitario.

Sin embargo, como bien señala Giuffra, ¿qué sucedería si la persona que -habiendo cumplido con los requisitos de Ley para obtener el registro sanitario-, decide luego elaborar los productos de manera anti higiénica e insalubre? Pues salvo que sea detectado por alguna autoridad competente, esa persona va a seguir comercializando sus productos de manera ilegal, con la correspondiente afectación a la salud pública.

Por tanto, ¿no habría que ir pensando ya en un mecanismo alternativo al registro sanitario de alimentos y bebidas industrializados? Coincido con Giuffra en que los esquemas de control ex post, principalmente en los establecimientos y procesos de producción (con sanciones drásticas en caso de incumplimiento), pueden resultar una vía más adecuada para garantizar que el comercio de estos productos sea conforme a Ley y sin afectar la salud de las personas. Agregaría que tendría que pensarse además

4 Disponible en: http://elcomercio.pe/opinion/mirada-de-fondo/guia-practica-hacermarcianos-franco-giuffra-noticia-1789149, 28 de febrero de 2015. 
en una especie de notificación sanitaria obligatoria similar a la que hoy regula el comercio de los productos cosméticos.

Para ello será necesario ciertamente dotar a las autoridades competentes del personal y capacitación suficientes, pero sobre todo de cambiar la mentalidad de controles previos que sigue enraizada en nuestra administración pública.

\section{V. ¿Son los Reglamentos de Establecimientos y de Productos Farmacéuticos válidamente aplicables en el Perú?}

En este punto simplemente quisiéramos dejar constancia de un aspecto formal respecto de la validez de los Reglamentos de Establecimientos y de Productos Farmacéuticos que no ha sido analizado debidamente.

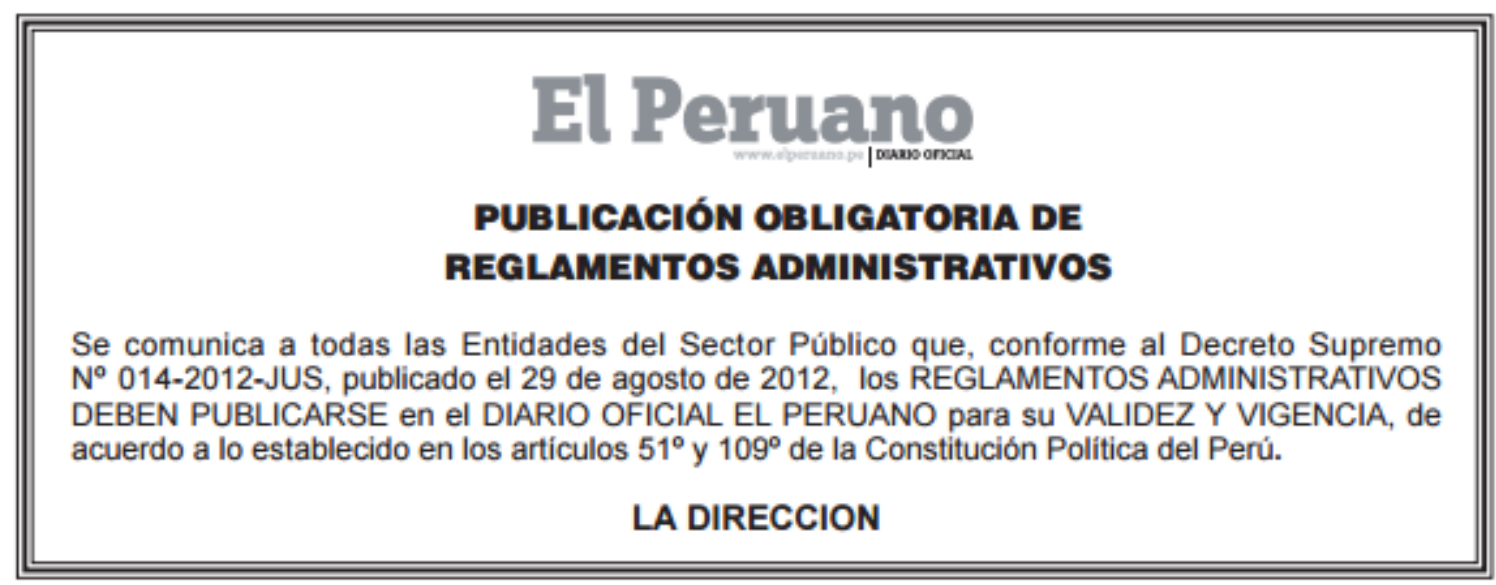

Al respecto, cada cierto tiempo se publica en la separata de Normas Legales del Diario Oficial El Peruano el siguiente anuncio ${ }^{5}$ :

Es decir, para que un Reglamento Administrativo tenga validez y vigencia en territorio peruano, éste debe ser publicado en el Diario Oficial El Peruano.

En ese sentido, el Artículo 109 de la Constitución Política del Perú dispone lo siguiente:

"Vigencia y obligatoriedad de la Ley

Artículo 109.- La ley es obligatoria desde el día siguiente de su publicación en el diario oficial, salvo disposición contraria de la misma ley que posterga su vigencia en todo o en parte."

$5 \quad$ Este anuncio fue publicado en la separata de Normas Legales del Diario Oficial El Peruano No 13194 del 23 de marzo de 2015 (p. 549223). 
Por su parte, el Decreto Supremo 001-2009-JUS (del 15 de enero de 2009), que aprueba el "Reglamento que establece disposiciones relativas a la publicidad, publicación de Proyectos Normativos y difusión de Normas Legales de Carácter General" establece en su artículo 7 lo siguiente:

"Artículo 4.- Alcance del concepto de las normas legales

Para efectos de lo dispuesto en el presente Reglamento, entiéndase por norma legal de carácter general a aquella que crea, modifica, regula, declare o extingue derechos u obligaciones de carácter general, de cuyo texto se derive un mandato genérico, objetivo y obligatorio, vinculando a la Administración Pública y a los administrados, sea para el cumplimiento de una disposición o para la generación de una consecuencia jurídica.

En tal sentido, se deben publicar obligatoriamente en el Diario Oficial El Peruano: (...)

\section{Los Decretos Supremos; (...)}

Artículo 7.- Publicidad obligatoria de las normas legales

La publicación oficial de las normas legales de carácter general es esencial para su entrada en vigencia. Las entidades emisoras son responsables de disponer su publicación en los términos y condiciones establecidas en el presente Reglamento, y normas complementarias.

Aquellas normas legales que no sean publicadas oficialmente, no tienen eficacia ni validez".

Debemos destacar que el precitado Decreto Supremo 001-2009-JUS se emitió como parte de los compromisos asumidos por el Estado peruano en el Tratado de Libre Comercio con los Estados Unidos, en cuyo Artículo 19.2 del Capítulo de Transparencia se acordó lo siguiente:

\section{"Artículo 19.2: Publicación}

1. Cada Parte se asegurará de que sus leyes, reglamentos, procedimientos, y resoluciones administrativas de aplicación general referentes a cualquier asunto comprendido en este Acuerdo, se publiquen prontamente o de otra forma sean puestos a disposición para conocimiento de las personas y Partes interesadas".

El 27 de julio de 2011 (el último día hábil del Gobierno correspondiente al período 2006 - 2011), se publicó en una "edición extraordinaria" de la separata de Normas Legales del Diario Oficial El Peruano los anteriormente mencionados Decretos Supremos 0142011-SA y 016-2011-SA (Reglamento de Establecimientos Farmacéuticos y Reglamento 
de Productos Farmacéuticos respectivamente), en cuyo Artículo 1 se menciona lo siguiente:

DS 014-2011-SA: "Artículo 1.- Aprobación

Apruébese el Reglamento de Establecimientos Farmacéuticos, que consta de quince (15) títulos, ciento cuarenta y seis (146) artículos, cinco (5) disposiciones complementarias finales, tres (3) disposiciones complementarias transitorias, una (1) disposición complementaria derogatoria y dos (2) anexos, cuyos textos forman parte integrante del presente Decreto Supremo y será publicado en el Portal del Estado Peruano (www.peru.gob.pe) y en el Portal Institucional del Ministerio de Salud (www.minsa.gob.pe) al día siguiente de la publicación de la presente norma en el Diario Oficial El Peruano".

DS 016-2011-SA: "Artículo 1.- Aprobación

Apruébese el Reglamento para el Registro, Control y Vigilancia Sanitaria de Productos Farmacéuticos, Dispositivos Médicos y Productos Sanitarios; que consta de siete (7) títulos, doscientos diez (210) artículos, siete (7) disposiciones complementarias finales, cuatro(4) disposiciones complementarias transitorias, una (01) disposición complementaria derogatoria y cinco (5) anexos, cuyos textos forman parte integrante del presente Decreto Supremo y será publicado en el Portal del Estado Peruano (www.peru.gob.pe) y en el Portal Institucional del Ministerio de Salud (www.minsa.gob.pe), al día siguiente de la publicación de la presente norma en el Diario Oficial El Peruano".

Ciertamente cuando se accede a las direcciones electrónicas mencionadas en ambos Decretos Supremos (www.minsa.gog.pe / www.peru.gob.pe), no se encuentra ninguna de estas normas. Los documentos que corresponden a los textos normativos de estos dos Decretos Supremos están en las siguientes direcciones electrónicas:

- Decreto Supremo 014-2011-SA:

ftp://ftp2.minsa.gob.pe/normaslegales/2011/DS014-2011-MINSA.pdf

- Decreto Supremo 016-2011-SA:

ftp://ftp2.minsa.gob.pe/normaslegales/2011/DS016-2011-MINSA.pdf

Sin embargo, la base de datos del Ministerio de Justicia y Derechos Humanos denominada "Sistema Peruano de Información Jurídica (SPIJ)" menciona lo siguiente respecto a estas dos normas legales: 
El caso del sector regulatorio sanitario

DS 014-2011-SA: "NOTA: Este Reglamento no ha sido publicado en el Diario Oficial "El Peruano", se descargó de la página web del Estado Peruano, con fecha 22 de diciembre de 2011." .

DS 016-2011-SA: "NOTA: Este Reglamento no ha sido publicado en el Diario Oficial "El Peruano", se descargó de la página web del Ministerio de Salud, con fecha 11 de enero de 2012".

Por lo anteriormente expuesto: ¿son los Reglamentos de Establecimientos y Productos Farmacéuticos dos normas publicadas ( $y$ en consecuencia vigentes) conforme a Ley?

No quisiera adelantar una respuesta definitiva, pero me inclino a pensar que por lo menos debería darse una discusión profunda sobre este hecho a efectos de abrir un espacio para tener la oportunidad de revisar y mejorar algunos aspectos de ambas normas.

Por poner sólo dos ejemplos: el Reglamento de Productos Farmacéuticos considera a los productos dietéticos en la categoría de productos farmacéuticos. ¿Es esto razonable? Creemos que no, pues los productos dietéticos no tienen una finalidad terapéutica como sí la tienen los productos farmacéuticos. Un segundo tema puede ser reevaluar la estructura misma de este Reglamento, ya que su redacción y contenido ha sido hecho sobre la base de un análisis de riesgo para productos farmacéuticos, sin considerar que los dispositivos médicos y -sobre todo- los productos sanitarios (especialmente los cosméticos), pueden entrar en categorías de riesgo distintas que no ameritan controles y requisitos tan estrictos como los fijados para los productos farmacéuticos.

A modo de conclusión, ante la problemática coyuntural que tenemos frente a las inversiones "macro", debemos ser imaginativos para identificar en aquellos sectores "micro" (en este caso, el sector de regulación sanitaria), algunas soluciones inmediatas que podrían generar una facilitación efectiva de las inversiones en este sector. 